\title{
Practical Epistemic Cognition in a Design Project- Engineering Students Developing Epistemic Fluency
}

Jonte Bernhard, Anna-Karin Carstensen, Jacob Davidsen and Thomas Ryberg

The self-archived postprint version of this journal article is available at Linköping University Institutional Repository (DiVA):

http://urn.kb.se/resolve?urn=urn:nbn:se:liu:diva-159874

N.B.: When citing this work, cite the original publication.

Bernhard, J., Carstensen, A., Davidsen, J., Ryberg, T., (2019), Practical Epistemic Cognition in a Design Project-Engineering Students Developing Epistemic Fluency, IEEE Transactions on Education, 62(3), 216-225. https://doi.org/10.1109/TE.2019.2912348

Original publication available at:

https://doi.org/10.1109/TE.2019.2912348

Copyright: Institute of Electrical and Electronics Engineers (IEEE)

http://www.ieee.org/index.html

(C)2019 IEEE. Personal use of this material is permitted. However, permission to reprint/republish this material for advertising or promotional purposes or for creating new collective works for resale or redistribution to servers or lists, or to reuse any copyrighted component of this work in other works must be obtained from the IEEE. 


\title{
Practical Epistemic Cognition in a Design Project - Engineering Students Developing Epistemic Fluency
}

\author{
Jonte Bernhard, Anna-Karin Carstensen, Jacob Davidsen and Thomas Ryberg
}

\begin{abstract}
Contribution: This work reports engineering students' practical epistemic cognition by studying their interactional work in situ. Studying "epistemologies in action" the study breaks away from mainstream approaches that describe this in terms of beliefs or of stage theories.

Background: In epistemology, knowledge is traditionally seen as "justified true belief", neglecting knowledge related to action. Interest has increased in studying the epistemologies people use in situated action, and their development of epistemic fluency. How appropriate such approaches are in engineering and design education need further investigation.

Research Questions: 1) How do students in the context of a design project use epistemic tools in their interactional work? 2) What are the implications of the findings in terms of how students' cognitive and epistemological development could be conceptualized?

Methodology: A collaborative group of six students were video recorded on the 14th day of a fifth-semester design project, as they were preparing for a formal critique session. The entire, almost six hour, session was recorded by four video cameras mounted in the design studio, with an additional fifth body-mounted camera. The video data collected was analyzed using video ethnographic, conversation analysis, and embodied interaction analysis methods.

Findings: The results show that the students use a wealth of bodily-material resources as an integral and seamless part of their interactions as epistemic tools, in their joint production of understanding and imagining. The analysis also suggests that students' epistemological and cognitive development, individually and as a group, should be understood in terms of developing "epistemic fluency".
\end{abstract}

Index Terms-Collaborative learning, design thinking, epistemology, epistemic cognition, epistemic fluency, interaction analysis, problem-based learning, video ethnography.

\section{INTRODUCTION}

"I $\mathrm{N}$ science we investigate the reality that is given; in technology we create a reality according to our designs" Skolimowski [1] points out. Consequently Mitcham [2] notes that design "constitutes the essence of engineering" since an engineer is "concerned with how things ought to be ... to attain

J. Bernhard is with the Department of Science and Technology (ITN), Linköping University, Campus Norrköping, Norrköping, Sweden (e-mail: jonte.bernhard@liu.se).

A.-K. Carstensen is with the School of Engineering, Jönköping University, Jönköping, Sweden (e-mail: anna-karin.carstensen@ju.se). goals and to function" [3]. Thus, the guiding question of this Special Issue "to what extent do design projects influence cognitive and epistemological development of undergraduates?" is of vital interest for engineering education.

Epistemology and the related adjective epistemic stem from the Ancient Greek word epistêmē meaning knowledge, what is known, or the way of knowing [4]. By tradition epistemology is considered as a branch of philosophy that investigates the nature, origins, scope, justification, and limitations of knowledge, that is, epistemology is a theory of knowledge [5] whereas the adjective epistemic typically means related to knowledge itself [4]. (However, this distinction is not always upheld in the literature and hence a considerable mixing of terms exists.) In traditional epistemology, knowledge is often seen as "justified true belief" although pragmatist philosophers like Rorty [6] held the view that "[we should not] view knowledge as a matter of getting reality right, but as a matter of acquiring habits of action coping with reality."

A fundamental question of an inquiry into students' "cognitive and epistemological development" would be what is it that develops. This means it would be essential to investigate how students' epistemic cognition in the context of engineering design can be conceptualized and understood, i.e., to study "how people acquire, construct, understand, justify, change, and use knowledge in ... contexts" [4]. Such an inquiry would be an inquiry into "knowledge ... as a matter ... of action coping with reality" [6]. Fundamental in studying human activity is to study the tools humans' use in the activity [7]-[10]. In the context of epistemic cognition it would, therefore be essential to study the tools and the use of epistemic tools, i.e., a conceptual, symbolic or physical tool purposefully used as a "tool of knowing" [11].

The questions explicitly addressed in this article are:

- RQ1 How do students in the context of a design project use epistemic tools in their interactional work?

- RQ2 What will be the implications of the findings in terms of how students' cognitive and epistemological development could be conceptualized?

To answer these research questions video data were collected

J. Davidsen is with the Department of Communication and Psychology, Aalborg University, Aalborg, Denmark (e-mail: jdavidsen@hum.aau.dk).

T. Ryberg is with the Department of Communication and Psychology, Aalborg University, Aalborg, Denmark (e-mail: ryberg@hum.aau.dk). 
to record students' activities in a design project, and these activities were analyzed using video-ethnographic and interaction analysis methods. Theoretical considerations related to published literature are also an important part of this study.

By asking these questions this study will be situated in the emergent strand of research that studies epistemology as a "social practice [that] entails seeing epistemology as constituted through situated interaction" [12], see also [13]-[18], with a focus on "knowledgeable action" [19].

\section{THEORETICAL BACKGROUND}

\section{A. Nature of Engineering and of Engineering Design}

It is extensively argued in the literature that engineering should be seen as a design science, as exemplified by [1], [2], [20]-[30] and as succinctly pointed out by Mitcham [2], that design is the "essence of engineering". Schön [21] describes designing as a complex process that involves numerous variables, constraints and conflicting values:

"Designing, in its broader sense involves complexity and synthesis. In contrast to analysts or critics, designers put things together and bring new things into being, dealing in the process with many variables and constraints, some initially known and some discovered through designing. Almost always, designers' moves have consequences other than those intended for them. Designers juggle variables, reconcile conflicting values, and maneuver around constraints - a process in which, although some design products may be superior to others, there are no unique right answers." [21]

In a similar vein Bucciarelli [22] remarks that "the methods of reduction and abstraction... fail to capture the collective nature of designing and design knowledge" Therefore, Samuel and Lewis [23] argue that "[analytical approaches] where there is heavy emphasis on solving problems with unique answers ... will fail in engineering design problems which have no unique answers", see for example [24]. Lavelle [25] notes that in engineering "efficiency and practical usefulness" are important values while in science "truth is [an] important" value. Furthermore, Layton [26] notes that "Engineering science often differs from basic science in important particulars. ... By its very nature, therefore, engineering science is less abstracted and idealized; it is much closer to the 'real' world of engineering. Thus, engineering science often differs from basic science in both style and substance. Generalizations about 'science' based on one will not necessarily apply to the other".

Consequently Skolimowski [1] maintains that "it is erroneous to consider technology as being an applied science" and accordingly Bucciarelli [22] argues "we can't teach design like we teach science". However, Owen [27] contended that science as well as design thinking is needed, thus it would be a mistake to conclude that knowledge of science does not matter. On the contrary, Samuel and Lewis [23] conjectured that robust understanding of concepts and fluency in their use as well as flexibility in transcending boundaries of knowledge domains are essential for an effective engineering designer.

Owen [27] has made an analysis in form of a conceptual "map" with four quadrants, Fig. 1, for different fields. On the vertical axis is symbolic or real content. On the horizontal axis are the processes, that is, the way a field works, displayed. A distinction is made between fields that are analytic, so more concerned with finding and discovering, and fields that are synthetic, so more concerned with making. According to Owen's analysis no field works entirely within a single quadrant, but in science the emphasis is on the analytic symbolic quadrant; the process is heavily analytic and its content is more symbolic than real, as subject matter is usually abstracted in its analysis. On the other hand, in Owen's mapping, design is highly synthetic and strongly concerned with the real world.

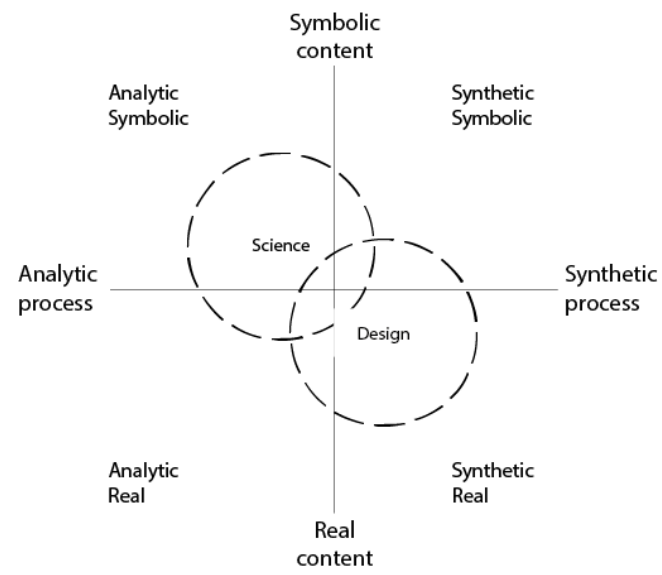

Fig. 1. Mapping of content and process factors in different fields, adapted from Owen [27].

Given these differences between science and engineering and design, it is reasonable to believe, paraphrasing Bucciarelli, that "we can't investigate the epistemologies and cognition students use in design like we do in science", see also [28], [29], [30]. Fundamental to an investigation into engineering students' epistemological and cognitive development is how epistemologies and cognition are enacted in students' actions. The questions asked by Cunningham and Kelly [31]- "what features are fundamental to the practice of doing engineering work?" and "how is ... engineering design and analysis different [from] other disciplinary areas"? - motivate the this study's interest in investigating the epistemic cognition engineering students use in practice, by studying how knowledge is used and created as epistemic tools by the students' in the activities of a design project.

\section{B. Engineering Epistemology}

By tradition, epistemology is considered as a branch of philosophy that investigates the nature, origins, scope, justification, and limitations of knowledge [5]. The view of "knowledge as a matter of getting reality right" [6] permeates much of the epistemological canon of the Western world. Other forms of knowledge than episteme and declarative knowledge were either rejected, or held in low regard and seen as involving only cognition at a low level. In accordance with this view engineering was seen as a "relatively straightforward and epistemologically uninteresting [application of scientific knowledge]" [13]. Consequently, Meijers and Kroes [32] claim that "modern epistemology has little to offer with respect to engineering knowledge".

Traditional epistemology, focusing on justified true belief, is 

10.1109/TE.2019.2912348. Please cite the published version if citing.

principally only adequate for declarative knowledge in engineering, but compared to science there is a fundamental difference in how this declarative knowledge is constituted and used. Science works with simplification, and with idealized, isolated objects, while engineering works with complexity, real entities and artefacts [20], [25], [26]. In most cases, for example, a mechanical engineer cannot neglect friction, and objects cannot be reduced to a point mass. Indeed, to paraphrase Rorty [6] an engineer needs to get the "reality right", but this needs to be related to the workings of real physical phenomena, not to idealized models of reality. Hence, as noted by Boon and Knuuttila [33], models have different epistemic purposes in science and in engineering; the focus in engineering is on the usefulness of a model in relation to context and the purpose for which it is going to be used. Thus, engineering is polyparadigmatic and the use of theory is eclectic [25].

In this context it might be appropriate to remember that Aristotle in his Nicomachean Ethics [34] saw not only episteme (true, justified belief), but also téchne (practical productive knowledge) and phrónesis (wisdom in practice) as important virtues of knowledge. Thus Henriksen [35], Malmberg [36], Bernhard [20] and others have argued for the importance of téchne and phronesis as virtues of knowledge in engineering education. An important implication of this discussion is that it would not be appropriate to see knowledge (and hence epistemological development) as synonymous with episteme (in a restricted sense) in the context of design (and engineering). Indeed, Kvanvig [37] argues that "truth is not the primary epistemic goal" and that the "[conception] of epistemology ... to be the theory of knowledge ... is too narrow". Instead he maintains that epistemology "in particular [should aim] to investigate successful cognition".

\section{Epistemic Cognition and Epistemic Fluency}

Studying epistemic cognition can be defined as examining "how people acquire, construct, understand, justify, change, and use knowledge in formal and informal contexts" [4].

In following Kvanvig's [37] call to "investigate successful cognition" the perspective of this work is explicitly pragmatic_-"noting that knowledge is purposeful, it occurs in a natural environment, and serves a functional role in that environment [and] individuals cognize in social contexts, situated in a material world" [16]. That is, this paper does not seek to describe epistemological development in terms of underlying cognitive constructs such as beliefs, as in [38], [39], say, or in terms of stage theories such as [40]-[43]. In in this it follows Elby, Macrander and Hammer [44], who call for "greater focus on documenting epistemologies in action"; see also [14], [45], [46].

The authors' view, [47], which follows that of Dewey [48], [49], Peirce [50], James [51] and Schön [28]; is that cognition can be seen as related to capabilities for action [7], [52]. and that cognition is, in fact, a specific action of the human body [11], [53], [54]. Indeed, the English word cognition stems from Latin cognoscere, meaning "to become acquainted with," "know" or "to come to know" [55]. The similarity of the original meanings of cognoscere (Latin) and of epistếmē (ancient Greek) is notable.

A fundamental aspect of investigating how students "come to know" and how they are using knowledge in action - that is, to study epistemic cognition - is to study the deliberate use of epistemic tools in activities. An epistemic tool is a conceptual, symbolic or physical tool purposefully used as a "tool of knowing" [11]. Consequently, an aspect of learning would be "learning through mastering epistemic tools" [19].

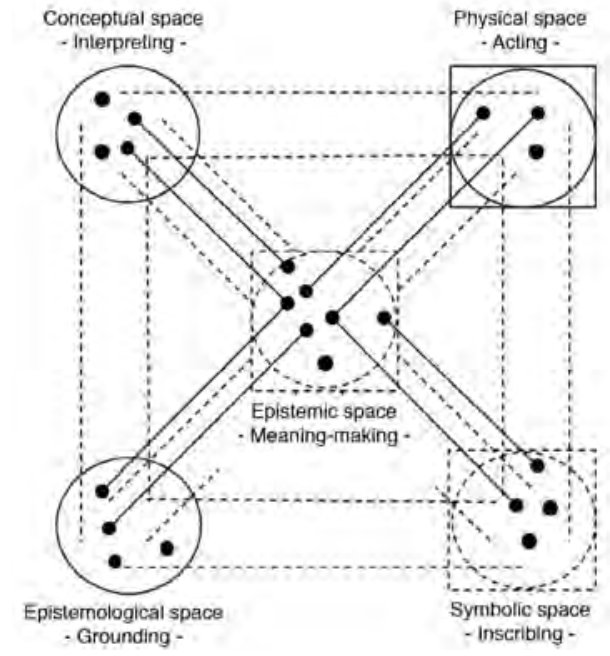

Fig. 2. The creation of an actionable epistemic space by blending and coordination as illustrated by Markauskaite and Goodyear [19].

Dashed lines represent general associations between the spaces; solid lines represent projections of selected elements into the blended epistemic space in a specific situation. (Reprinted with permission from Springer)

One problem, according to Markauskaite and Goodyear [19], is that the "epistemic complexity of knowledgeable action is underestimated" and "higher education sometimes oversimplifies the epistemic qualities of professional tools". Rather, professional knowledgeable action requires "fluent use of semiotic and material tools, body and environment". As illustrated in Fig. 2, this requires the weaving together, blending and co-ordination of a conceptual, physical, epistemological and symbolic space to establish an epistemic space. Thus, epistemic fluency [19], [56] would involve "both an ability to move smoothly between the abstract, contextual and situated ways of knowing and a capacity to employ multiple ways of knowing provided by the senses, environment and imagination to construct actionable understanding" [19].

The capacity to employ multiple ways of knowing has previously been investigated by the first two authors in the context of labs in electrical engineering [57]. From analysis of video recordings of students' courses of actions [58] they constructed what they called the "learning of complex concepts" (LCC-model) [59]-[62]. An example of an analysis, and subsequent modeling, is displayed in Fig. 3. Identified epistemic objects are illustrated by circles and the links the studied lab-group were able to make during the lab are illustrated by arrows. The shaded circles in the figure represent epistemic objects located in the "world" of objects/events and the other circles the "world" of theories/models according to a categorization proposed by Tiberghien [63]. In the LCC-model learning can be seen as the making of these links by students. 
This means that learning, knowledge and understanding is not seen as an either/or thing. Rather, learning is seen as becoming "richer" the more links that were established. In the authors' understanding this view is closely related, although somewhat differently expressed, to the view of learning as "mastering epistemic tools" [19] and to epistemic fluency.

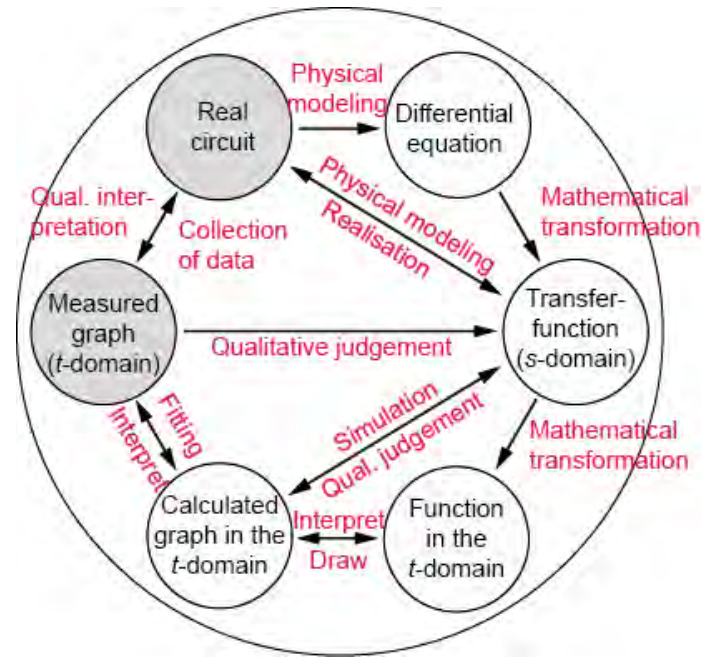

Fig. 3. An example from previous research of how mastering epistemic fluence can be presented [59]-[62]. The figure show the links a student group made during a lab in which they had to model (design models of) transient response in some electric circuits. Short labels for the associated epistemic practices of links are included in the figure.

\section{METHOD}

\section{A. Study Context}

To answer the research questions a group of architecture and design (A\&D) students participating in a design project at Aalborg University (AAU), Denmark, were studied. The A\&D program at AAU includes elements of architecture education, but also builds on knowledge, skills and competencies from engineering. In the Danish context this was a novel approach when the program started in the 1990s, as traditionally the fields of architecture and engineering are separated. The creation of the A\&D program was an attempt to combine the "technical theoretical" knowledge of engineering with the "aesthetic and artistic" artisanship of architecture, to create a new interdisciplinary education.

In general, at AAU the students in all programs work in groups with Problem Based Learning (PBL) modules each semester according to PBL-model known as the Aalborg model [64], [65]. They work in groups each semester over a period of approximately two to three months identifying, formulating and analyzing a problem related to their field of study. The process is facilitated by a project supervisor, who act as a critical dialogue partner. The 'solution' to the problem is discussed in a final project report and assessed through a group based oral exam. The PBL-project is typically worth 15 ECTS and the remaining credits for the semester (15 ECTS) are assessed through courses that run throughout the semester with the intention to support the students' project work [64], [65].

In the $A \& D$ program the students are allocated a workspace in an open learning environment - this is referred to as a design studio. Each semester the students spend time organizing the studio to meet their requirements for a good learning space during the course of the project work the studio is also rearranged to align with the different phases of their project [66]. To an outsider the studio looks messy, with all sorts of materials on the boards and tables, Fig. 4, but for the students this melting pot of materials and resources serves as a constant reminder of the problem, project and process

The module analyzed in this study was completed in the fifth semester, where the A\&D students are tasked with designing an office building for an external partner. The overall theme of the project is an "Energy Optimized Building," valued at 15 ECTS. The specific goals of this module are described as:

The purpose of the module is to enable students to design a building that can provide a framework for a specific function, typically a semi-public building. The building must include space for office work or teaching, characterized by the fact that both individual and joint work are performed. The student must be able to incorporate energy and indoor climate-optimizing measures into the architectural design and be able to include the building's context, aesthetics and special requirements for spatial organization and different work functions. (Authors' translation)

This project module is shorter than traditional modules at AAU, lasting only six weeks.

\section{B. Data Collection and Analysis}

An investigation into practical epistemic cognition studies how knowledge and epistemic tools are used in an activity [15]. The data analyzed in this paper is from a period 14 days into the project work, where a student group (four females, two males) is preparing to take part in a formal critique session the next day. After the review session the groups have approximately four weeks left to complete their design of the building.

The interactions [58], [67], [68] within the group and with other groups was recorded using five digital camcorders, including one body-mounted GoPro camera) during complete sessions - in this case the session lasted almost six hours. To facilitate analysis, recordings were synchronized - the still photo in Fig. 4 shows how the group's interactions were captured simultaneously. This video recording is part of a wider corpus consisting of approximately 500 hours of video data from five groups (three groups participated for the entire project period, while two groups decided to leave the project after two weeks).

The preparation for the critique session was selected for analysis as it is what Jordan and Henderson [58] refer to as a natural unit of analysis - limited in time and with a particular purpose. The strategy suggested by Jordan and Henderson was followed and what they refer to as an "unmotivated looking" through the video data was performed. After repeated viewings, some episodes were found to contain more interesting activities from the point of view of the research questions, i.e., parts 


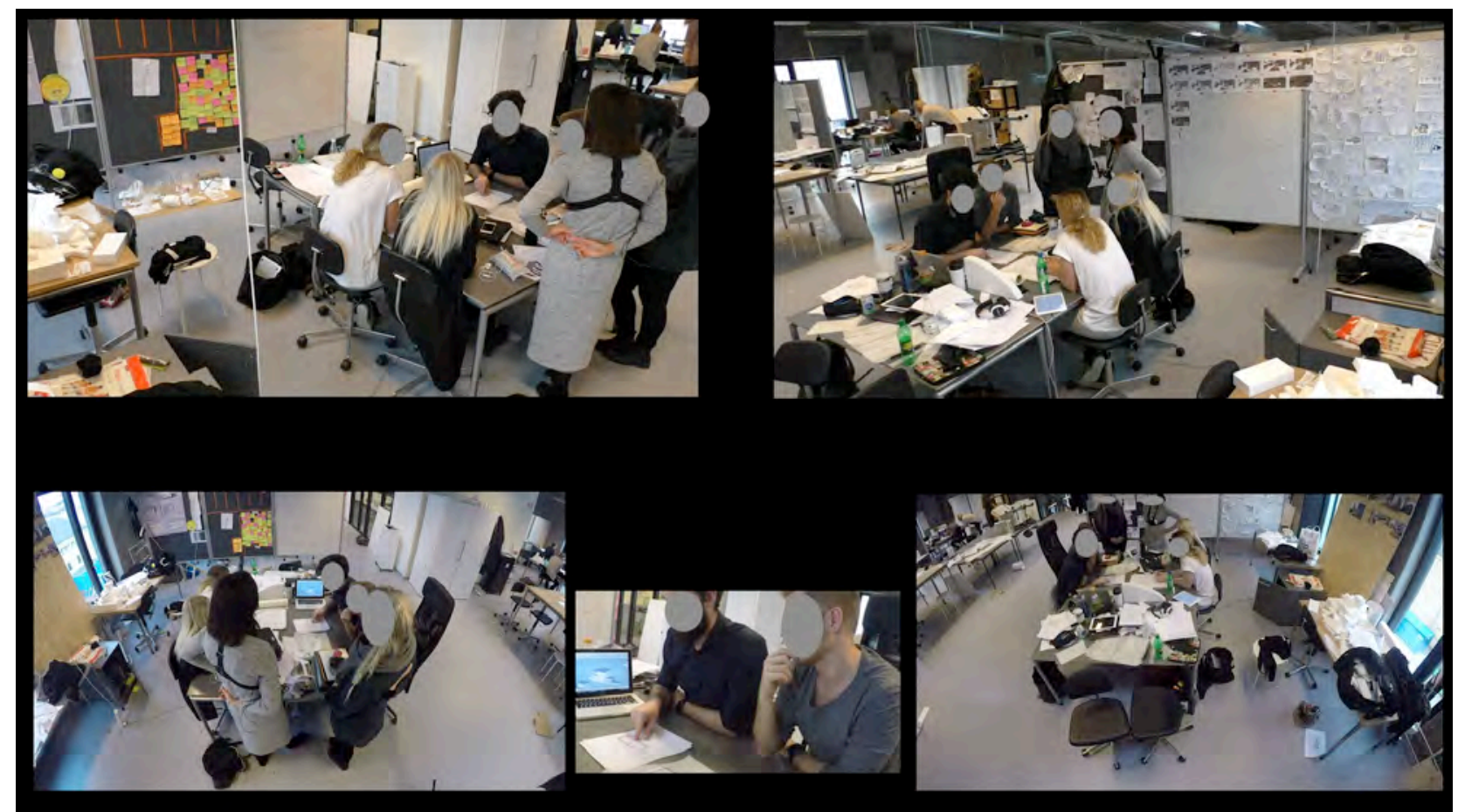

Fig. 4. Frame grab from stitched-together synchronized video recordings that show one group of students seen by multiple cameras. All pictures display the groups' activities at the same time, but from different viewpoints.

where students made extensive use of epistemic tools in their interactional work. Particularly interesting sequences were transcribed for detailed examination of interactional patterns. In the original Danish transcriptions, standard Jefferson conventions used in conversation analysis were used [69], [70].

The transcripts included in this paper were translated from Danish into English. As noted by Linell and Persson Thunqvist [71] "translation of naturally occurring talk-in-interaction is a difficult task, and it is impossible to make the transcriptions match the originals at all points". In the translation the focus has been on conveying the meaning of students' talk, rather than attempting to present a "true" word-by-word translation including prosodic and linguistic features such as rhythm, intonation and voice quality, features that would be difficult to translate.

The study was conducted under the ethical guidelines in place at Aalborg University and at Linköping University, Sweden, in accordance with Danish and Swedish laws. Informed consent forms were signed by each research participant. In this paper, participants have been given pseudonyms (Mette, Heidi, Sven, Ina and Sine) and faces have been blurred to protect their anonymity and to avoid tracing their identity in the data.

\section{FINDINGS}

The groups in this PBL design project have their own designated workspace-resembling what architects traditionally refer to as a studio [21], [43]. The boards surrounding the workspace (and serving as dividers from other groups' workspaces) are cluttered with drawings, sketches, photographs, and sticky notes, Fig. 4. These serve as a historical trajectory of materials and design ideas, constantly present for the student group.

Although the general findings and analysis presented in this paper are based on an analysis of the complete six hours of video, limited space means only one short excerpt from the video data analysis can be presented here. This, Excerpt 1, was chosen as it highlights the findings related to the research questions, especially RQ1.

Excerpt 1 starts 4 hours 32 minutes into the session. During that time the students had been working to finalize different design proposals, as a group but also in shifting subgroups of one, two or three students approaching a particular problem. This group is quite social; they started the day by eating breakfast together, just before the excerpt starts they had lunch, and then came together as a whole group in a self-organized peer-review session. Immediately before Excerpt 1 starts the students are discussing how to address some design problems. Mette fetches a 3D model consisting of four separate layers ("floors") made of foam. Heidi, supported by Sine suggests that the top floor of the building should be slightly shifted to complete the shape of the building and allow for a passage. Mette takes up Heidi's suggestion and turn 1, and the associated picture, shows her demonstrating how this solution might work. As the layers of the 3D-model were not glued together she could move the floors independently to show a feasible solution. The actions in excerpt 1 unfold over $34 \mathrm{~s}$, with each conversational turn being listed in Table I. 
10.1109/TE.2019.2912348. Please cite the published version if citing.

Table I: Turns and actions from Excerpt 1. Comments and description of actions are enclosed between double parenthesis ((action)), and some turns show still pictures of representative embodied action during that turn.
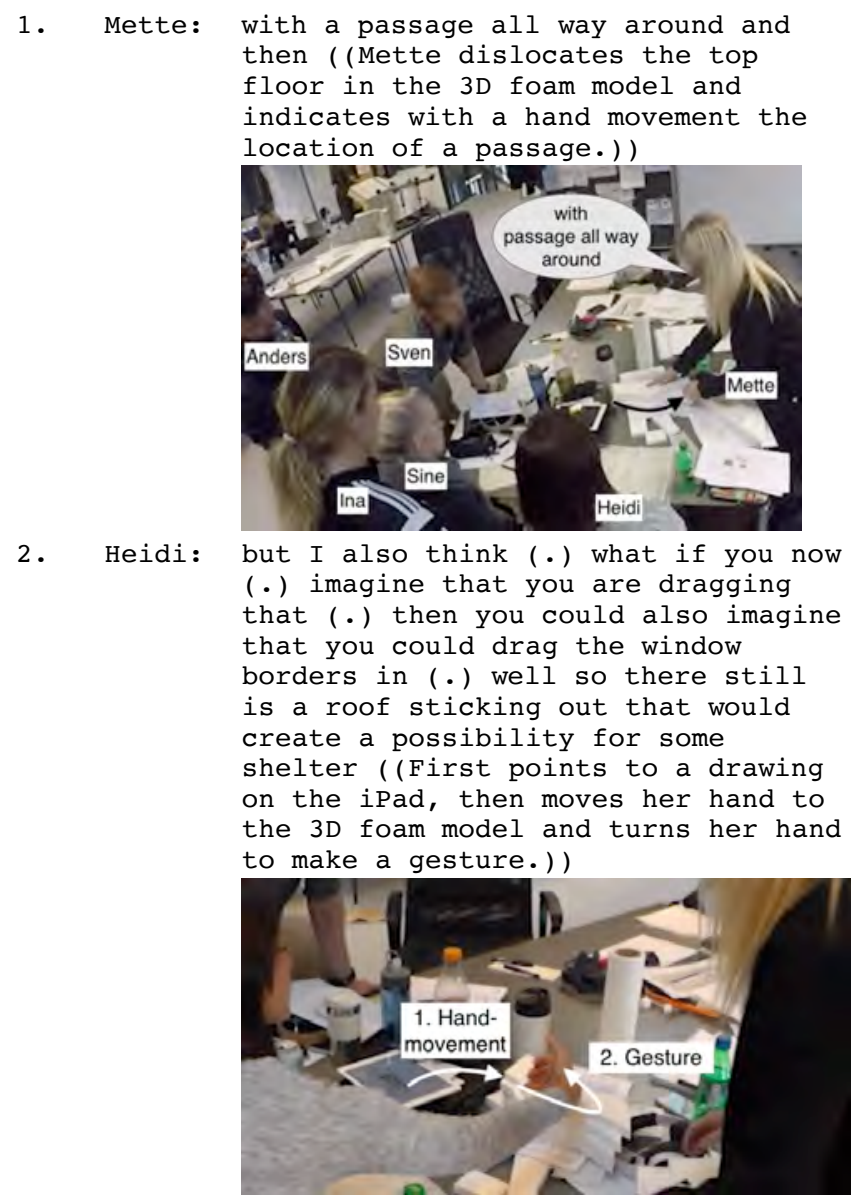

3. Ina:
4. Sine:

\section{yeah}

yeah precisely ( (Mette goes to a table on the side and fetches a drawing))

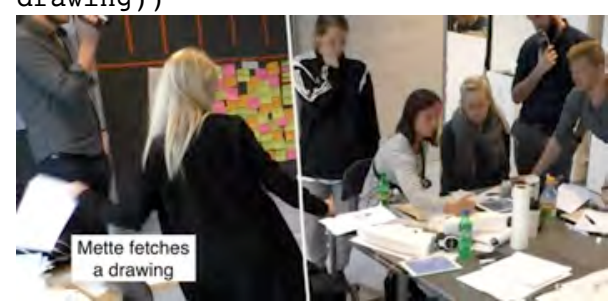

5. Heidi: for example (if one had it here)

6. Ina: that could also work

7. $(1.9)$

8. Heidi: yeah but ((Points to the 3D-foam model))

9. Ina: is it

10. Heidi: Here, here is the window (.) but there is still a roof here for example and then you actually have a room up here

((Points on the 3D-foam model))

11. Ina: yes (.) and it was actually here ((Moves closer, leans forward, and points on the 3D-foam model))

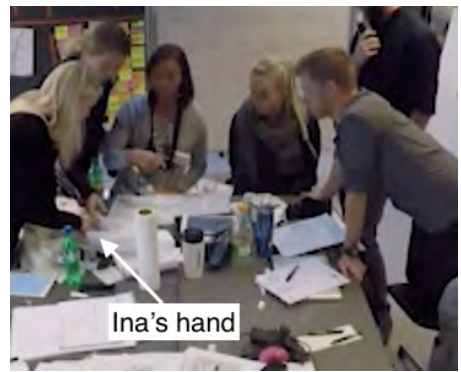

12. Mette: I was in some doubt what you meant

(.) so with window borders on ((Points in drawing))

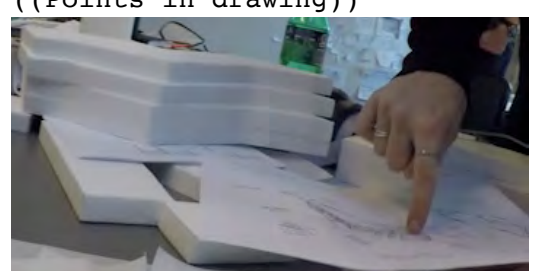

13. Heidi: eh: : yes if one imagines something there also ( (Heide points to the drawing and Sven makes a gesture with his right hand))

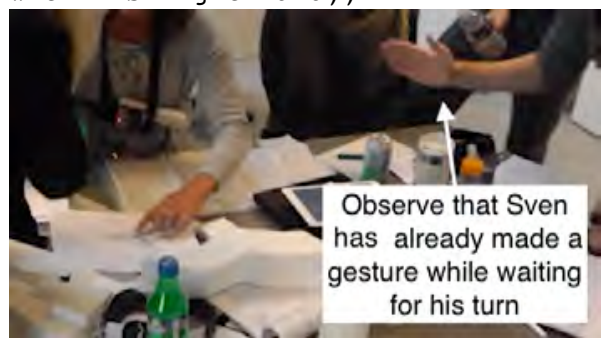

14. Sven: (if) you to pull it back

15. Ina: but you keep the shape

16. Heidi: the window is maybe actually (0.6) here ( Makes a gesture in relation to the 3D-foam model))

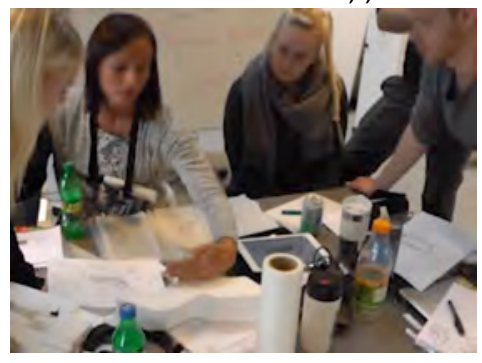

For the analysis of this excerpt, it should be noted that this was a very short conversation, lasting a little over 34 seconds. A first point to notice is that talk, gestures and the use of different artefacts are intimately used in the students' collaboration. Quite complex interactional and epistemic work can be seen in the stitched together videos and transcript; the still photos can only partially render the very rapid interactions. The six students are simultaneously trying to construct and elaborate a common understanding of the design problem on hand and to discuss different proposals for solving it. Students seamlessly and rapidly shift between using the 3D-foam model, a drawing on an iPad, a drawing on paper, and gestures. Although everything happens very rapidly, they seem to be able to understand each other and follow each other's suggestions. Indeed, the fast pace of interaction and the absence of requests 
for clarification suggest that they share an adequate understanding of the ideas and proposals.

In the excerpt it can be seen that gestures [72] are used indexically by speakers to indicate what $\mathrm{s} / \mathrm{he}$ is referring to or to demonstrate a feature of the imagined and concrete building. In the complete video recordings, although not clearly visible in this excerpt, students also used gestures to make "gestured drawings" [73] in the air to substitute for making a quick sketch or to enhance an argument.

Throughout the session the students made extensive use of drawings, either done by hand on paper, done on various iPads, or CAD-drawings done on their laptop computers, as well as making quick sketches on paper during ongoing discussions. For example, in students' ongoing discussion of the advantages and disadvantages of the design solution with a shifted top floor, that continued for some time after the end of the interaction presented in excerpt 1 , the students made ample use of the 3D foam model. In this discussion the foam model's 3D features, that meant it could be rotated and viewed from different angles, for example, were extensively used.

These findings demonstrate that this group of students used a multitude of bodily-material resources, presented above, as epistemic tools. Furthermore, the uses of these epistemic tools are fluent, coordinated, and woven together suggesting that these students have developed a high degree of epistemic fluency [19] and have a good ability to "make links" [60] between different epistemic objects.

\section{DISCUSSION}

The theme of this special issue is, as already mentioned, the role of participation in design projects to students' "cognitive and epistemological development". The findings presented above indicate that the students were skilled in using different resources as epistemic tools and had achieved a high degree of epistemic fluency.

This study alone may not sufficiently demonstrate the development of epistemic fluency. However, if other studies are also considered it is quite reasonable to believe that the high degree of epistemic fluency observed among the students, individually and as a group, in this study is the result of development. Indeed, the first author has, within a pilot study, made some observations within a design project in the first year of the Swedish upper secondary school (16-17 years old). Compared to the university students in this study, the secondary school students displayed a much lower degree of epistemic fluency. Using similar methods as in this study the first author [74] also found that third-year electrical engineering students used oscilloscopes fluently as epistemic tools, while first-year students lacked this ability. In studies made in artificial settings, using verbal protocol analysis, Atman and co-workers found that skilled designers scoped problems more effectively than less skilled or experienced designers, such as students, by considering more objects and making more back-and-forth transitions between design steps, that is, epistemic objects, see for example [75], [76], [77]. Furthermore, Wolmarans [78], [79] found that the quality of students' designs was very much dependent on how the team managed to use "disciplinary knowledge" as an epistemic tool. Successful student design teams displayed an understanding of linking and applying abstract reasoning to the material practicalities in a design situation, but they also understood which theoretical and conceptual knowledge was appropriate to use in a practical situation. In the terminology of Markauskaite and Goodyear [19] they were able to make (theoretical) knowledge actionable and (practical) action knowledgeable.

Thus, studying students' development of epistemic fluency in situ would be a valid and appropriate method to study students' epistemological development, thus documenting "epistemologies in action" [44]. This means a break away from mainstream approaches describing epistemological development in terms of beliefs or in terms of stage theories. The validity of the stage models have been questioned, for example in [80], and what counts as a sophisticated epistemology in these models have also been questioned, as in [13], [45]. Although it is beyond the scope of this paper to go into this debate, it is important to note the difference between studying students' "epistemologies in action" and studying students' epistemological views through interviews or questionnaires. It is well known that what students' say in interviews or answer in questionnaires quite often does not correspond with what they do in reality, see for instance [81], thus it is essential to study real activities in situ.

Furthermore, in regard to methodology, the use of video ethnographic and embodied interaction analysis methods in this study made it possible ] to do a fine-grained investigation of the interactional work students do and the resources they use to collaborate and complete tasks as teams, see also [82]. This has enabled the study in situ of how students' daily activities are materially, bodily, and interactionally organized, as well as of details of individuals' actions and the conceptual and material resources used. Given the quick pace of student interactions in the excerpt, it would have been nearly impossible to capture these interactions with other methods. Indeed, in several instances important details were first noted after repeated viewings of the videos. The use of multiple video cameras also made it possible to get a better view, or in some cases, even get a view of how epistemic tools were used or of gestures made.

The study show that the students used of a wealth of bodilymaterial resources as an integral and seamless part of their interactions in their joint production of understanding and imagining. The use of bodily resources (e.g., gestures, utterances, bodily orientations), concrete materials (e.g., 3Dfoam models, paper models), "low-tech" inscriptions (e.g., sketches, drawings on paper, sticky notes) and "high-tech" inscription devices (e.g., CAD-drawings) was heavily interwoven and difficult to separate. These findings stand in contrast to the cognitivist "presumption that all psychological explanation must be framed in terms of internal mental representation, and processes" [83]. A consequence of this presumption is that material resources inherently have no, or low, "cognitive value" [84]. On the contrary, this study demonstrates that material resources can have value as epistemic tools. Moreover, the use of bodily-material resources as epistemic tools transcended the boundaries of the individuals, and became tools for the group's collaborative thinking, thereby fostering connection between individual cognition and collective re-cognition, see also [85], [86], [87]. Thus, "distributed cognition" [85], [88], [89] is clearly visible 
in our findings; achievements do not only arise from individuals' thinking, but also through collaborative thinking distributed among the members in the teams and from the use of bodily-material resources used as epistemic tools. Indeed, according to Stahl [90], [91], collaborative groups build knowledge through shared understanding, co-construction, and interaction in a joint problem space; he thus proposes that studies of group cognition should build on post-cognitive theories, see also [47].

As mentioned previously, Aristotle [34] saw téchne (practical productive knowledge), and phrónesis (practical wisdom) as important virtues of knowledge in addition to episteme. These forms of knowledge have not been discussed in this paper, yet it is clear that téchne as well as phrónesis are clearly visible as forms of knowledge in the students' interactions. Making well-grounded and ethical design decisions requires practical wisdom using knowledge of the situation at hand through the fluent use of epistemic tools. Indeed, the need for practical wisdom in professional practice have achieved a considerable interest, for example [29], [30], [92].

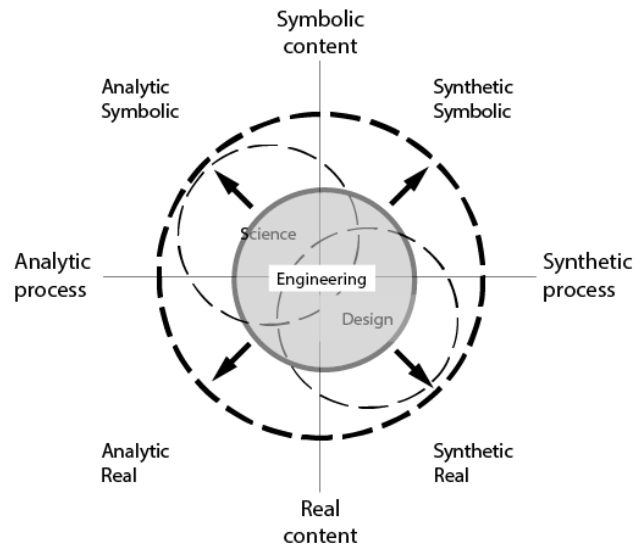

Fig. 5. A model of knowledge development (based on Owen's model [27]).

Taken together, this study's empirical findings and the literature point to the value of understanding epistemological and cognitive development in ways other than those commonly used in mainstream approaches. Seeing development in terms of developing "actionable knowledge" as well as "knowledgeable action" [19] requires the development of epistemic fluency. Epistemic fluency implies the weaving together of conceptual, physical, epistemological and symbolic spaces to develop an epistemic space, see [60]. If this is interpreted in light of Owen's model [27], Fig. 1, this would imply that for "science" knowledge to become "actionable knowledge" it should, metaphorically, move in the direction of origin in Fig. 5 and involve aspects of knowledge and knowing from all four quadrants. In a similar vein for "design" knowledge to become "knowledgeable action", it should also move in the direction of origin and involve all four quadrants. Fused together they form engineering knowledge; metaphorically development would be that growth of knowledge and abilities in all directions as indicated by the arrows in Fig. 5.

\section{CONCLUSION}

This study has shown that a group of students studied in a fifth semester design project fluently used used a multitude of bodily-material resources as epistemic tools (RQ1). It is suggested that students' epistemological and cognitive development should be studied through the study of epistemic cognition in situ as "epistemologies in action," and that development could be conceptualized as the development of epistemic fluency; that is, the fluent, integrated and appropriate use of epistemic tools in context (RQ2).

To validate the suggestion of operationalizing epistemological and cognitive development as the development of epistemic fluency, the authors propose that in situ studies of "epistemologies in action", i.e., practical epistemic cognition, should be performed in settings other than that reported here. Video-recordings have been made in design projects in the first and the fourth semester of the A\&D program at AAU, but the analysis of these video recordings has yet to be started. Studies at Linköping University are planned. The authors hope to report the findings from such complementary studies in the future.

\section{REFERENCES}

H. Skolimowski, "The structure of thinking in technology," Technology and Culture, vol. 7, no. 3, pp. 371-383, 1966.

C. Mitcham, Thinking Through Technology: The Path between Engineering and Philosophy. Chicago: The University of Chicago Press, 1994

H. Simon, The Sciences of the Artificial, 3rd ed. Cambridge, MA: The MIT Press, 1996.

J. A. Greene, W. A. Sandoval, and I. Bråten, "Handbook of epistemic cognition." New York: Routledge, 2016.

S. Bernecker and D. Pritchard, "The Routledge Companion to Epistemology." New York, NY: Routledge, 2011.

R. Rorty, Objectivity, relativism, and truth: Philosophical papers volume 1. Cambridge: Cambridge University Press, 1991.

M. Cole and J. Derry, "We have met technology and it is us," in Intelligence and technology: The impact of tools on the nature and development of human abilities, R. J. Sternberg and D. D. Preiss, Eds. Mahwah: Lawrence Erlbaum, 2005, pp. 209-227.

[8] G. McDonald, H. Le, J. Higgins, and V. Podmore, "Artifacts, tools, and classrooms.," Mind, Culture \& Activity, vol. 12, no. 2, pp. 113127,2005

[9] R. Miettinen, "Artifact mediation in Dewey and in culturalhistorical activity theory," Mind, Culture \& Activity, vol. 8, no. 4, pp. 297-308, 2001.

[10] L. S. Vygotsky, Mind in Society: The Development of Higher Psychological Processes. Cambridge: Harvard University Press, 1978

[11] J. Dewey, "Experience and nature," in John Dewey: The Later Works, vol. 1, J. A. Boydston, Ed. Carbondale: Southern Illinois University Press, 1925/1981.

[12] G. Kelly, S. McDonald, and P.-O. Wickman, "Science Learning and Epistemology," in Second International Handbook of Science Education, vol. 24, B. J. Fraser, K. Tobin, and C. J. McRobbie, Eds.: Springer Netherlands, 2012, pp. 281-291.

[13] V. Kant and E. Kerr, "Taking Stock of Engineering Epistemology: Multidisciplinary Perspectives," Philosophy \& Technology, 2018.

[14] P.-O. Wickman, "The Practical Epistemologies of the Classroom: A Study of Laboratory Work," Science Education, vol. 88, pp. 325344, 2004

[15] G. J. Kelly, "Methodological considerations for the study of epistemic cognition in practice," in Handbook of epistemic cognition, J. A. Greene, W. A. Sandoval, and I. Bråten, Eds. New York: Routledge, 2016, pp. 393-408.

[16] S. Knight and K. Littleton, "Socialising Epistemic Cognition," Educational Research Review, vol. 21,pp. 17-32, 2017. 


\subsection{9/TE.2019.2912348. Please cite the published version if citing.}

[17] H. G. Hoffmann Michael and W.-M. Roth, "What you should know to survive in knowledge societies: On a semiotic understanding of 'knowledge'," Semiotica, vol. 157, no. 1/4, pp. 105-142, 2005.

[18] B. Ewenstein and J. Whyte, "Knowledge Practices in Design: The Role of Visual Representations as `Epistemic Objects'," vol. 30, no. 1,pp. 07-30, 2009.

[19] L. Markauskaite and P. Goodyear, Epistemic Fluency and Professional Education: Innovation, Knowledgeable Action and Actionable Knowledge. Dordrecht: Springer, 2017.

[20] J. Bernhard, "Engineering education research as engineering research," in International perspectives on engineering education: Engineering education and practice in context, volume 1, S. Hyldgaard Christensen, C. Didier, A. Jamison, M. Meganck, C. Mitcham, and B. Newberry, Eds. Cham: Springer, 2015, pp. 393414.

[21] D. A. Schön, Educating the Reflective Practitioner: Toward a New Design for Teaching and Learning in the Professions. San Francisco: Jossey-Bass, 1987.

[22] L. L. Bucciarelli, "Design Knowing \& Learning: A Socially Mediated Activity," in Design Knowing and Learning: Cognition in Design Education, C. Eastman, W. Newstetter, and M. McCracken, Eds. Oxford: Elsevier, 2001, pp. 297-314.

[23] A. E. Samuel and J. G. Weir, "The acquisition of wisdom in engineering design," Instructional Science, vol. 20, no. 5, pp. 419$442,1991$.

[24] C. L. Dym, A. M. Agogino, O. Eris, D. D. Frey, and L. J. Leifer, "Engineering Design Thinking, Teaching, and Learning," Journal of Engineering Education, vol. 94, no. 1, pp. 103-120, 2005.

[25] S. Lavelle, "Technology and engineering in context: Analytical, phenomenological and pragmatic perspectives," in Engineering in context, S. Hyldgaard Christensen, B. Delahousse, and M. Meganck, Eds. Aarhus: Academica, 2009, pp. 75-95.

[26] E. T. Layton, "American ideologies of science and engineering," Technology and Culture, vol. 17, no. 4, pp. 688-701, 1976.

[27] C. Owen, "Design Thinking: Notes on its Nature and Use," Design research quarterly, vol. 2, no. 1,pp. 16-27, 2007.

[28] D. A. Schön, The Reflective Practitioner: How Professionals Think in Action. New York: Basic Books, 1983.

[29] T. Cosgrove and J. O'Reilly, "Theory, practice and interiority: an extended epistemology for engineering education," European Journal of Engineering Education, 2018.

[30] J. Dunne, Back to the Rough Ground: 'Phronesis' and 'Techne' in Modern Philosophy and in Aristotle. Notre Dame, IN: University of Notre Dame Press, 1993.

[31] C. M. Cunningham and G. J. Kelly, "Epistemic Practices of Engineering for Education," Science Education, vol. 101, no. 3, pp. 486-505, 2017.

[32] A. Meijers and P. A. Kroes, "Extending the Scope of the Theory of Knowledge," in Norms in Technology, M. J. de Vries, S. O. Hansson, and A. Meijers, Eds. Dordrecht: Springer, 2013, pp. 1534.

[33] M. Boon and T. Knuuttila, "Models as epistemic tools in engineering sciences," in Philosophy of Technology and Engineering Sciences, A. Meijers, Ed. Amsterdam: North-Holland, 2009, pp. 693-726.

[34] Aristotle, Nicomachean Ethics. Kitchener: Batoche Books, 1925/1999.

[35] L. B. Henriksen, "Engineers and bildung," in Engineering science, skills and bildung, J. Christensen, L. B. Henriksen, and A. Kolmos, Eds. Aalborg: Aalborg University Press, 2006, pp. 43-60.

[36] R. Malmberg, Analog circuit topology development: Practice methods for technology and teaching based on comprehensible transitor models (Doctoral dissertation). Gothenburg: Chalmers University of Technology, 2007.

[37] J. Kvanvig, "Is truth the primary epistemic goal.," in Contemporary Debates in Epistemology, M. Steup, J. Turri, and E. Sosa, Eds. Second ed. Chichester, UK: John Wiley, 2014, pp. 352-362.

[38] M. Schommer, "Effects of beliefs about the nature of knowledge on comprehension," Journal of educational psychology, vol. 82, no. 3, p. 498,1990 .

[39] M. Schommer-Aikins, "Explaining the epistemological belief system: Introducing the embedded systemic model and coordinated research approach," Educational psychologist, vol. 39, no. 1, pp. 1929,2004 .
[40] W. G. Perry, Forms of ethical and intellectual development in the college years: A scheme. San Fransisco: Wiley, 1970.

[41] R. M. Marra, B. Palmer, and T. A. Litzinger, "The Effects of a FirstYear Engineering Design Course on Student Intellectual Development as Measured by the Perry Scheme," Journal of Engineering Education, vol. 89, no. 1, pp. 39-45, 2000.

[42] M. J. Pavelich and W. S. Moore, "Measuring the Effect of Experiential Education Using the Perry Model," Journal of Engineering Education, vol. 85, no. 4, pp. 287-292, 1996.

[43] S. M. Chance, J. Marshall, and G. Duffy, "Using architecture design studio pedagogies to enhance engineering education," International Journal of Engineering Education, vol. 32, no. 1(B), pp. 364-383, 2016.

[44] A. Elby, C. Macrander, and D. Hammer, "Epistemic cognition in science," in Handbook of epistemic cognition, J. A. Greene, W. A. Sandoval, and I. Bråten, Eds. New York: Routledge, 2016, pp. 113127.

[45] C. A. Chinn and R. W. Rinehart, "Epistemic cognition and philosophy: Developing a new framework for epistemic cognition," in Handbook of epistemic cognition, J. A. Greene, W. A. Sandoval, and I. Bråten, Eds. New York: Routledge, 2016, pp. 460-478.

[46] C. A. Chinn, L. A. Buckland, and A. L. A. Samarapungavan, "Expanding the Dimensions of Epistemic Cognition: Arguments From Philosophy and Psychology," Educational Psychologist, vol. 46, no. 3, pp. 141-167, 2011.

[47] J. Bernhard, "Humans, intentionality, experience and tools for learning: Some contributions from post-cognitive theories to the use of technology in physics education," AIP Conference Proceedings, vol. 951, no. 1, pp. 45-48, 2007.

[48] J. Dewey, "How We Think: A Restatement of the Relation of Reflective Thinking to the Educative Process," in John Dewey: The Later Works, vol. 8, J. A. Boydston, Ed. Carbondale: Southern Illinois University Press, 1986.

[49] J. Dewey, "Logic: The Theory of Inquiry," in John Dewey: The Later Works, vol. 12, J. A. Boydston, Ed. Carbondale: Southern Illinios University Press, 1938/1986.

[50] C. S. Peirce, "How to make our ideas clear," Popular Science Monthly, vol. 12, pp. 286-302, 1878.

[51] W. James, The Principles of Psychology. New York: Henry Holt, 1890.

[52] J. V. Wertsch, Mind as Action. Oxford: Oxford University Press, 1998.

[53] J. Dewey, "The reflex arc concept in psychology," Psychological Review, vol. 3, pp. 357-370, 1896.

[54] A. Noë, Action in Perception. Cambridge: The MIT Press, 2004.

[55] Oxford English Dictionary, "cognition, n.," Oxford English DictionaryOxford: Oxford University Press. [Online]. Available: http://www.oed.com/view/Entry/35876?redirectedFrom=cognition.

[56] D. Morrison and A. Collins, "Epistemic fluency and constructivist learning environments," Educational Technology, vol. 35, no. 5, pp. 39-45, 1995.

[57] A.-K. Carstensen and J. Bernhard, "Student learning in an electric circuit theory course: Critical aspects and task design," European Journal of Engineering Education, vol. 34, no. 4, pp. 389-404, 2009. B. Jordan and A. Henderson, "Interaction Analysis: Foundations and Practice," The Journal of the Learning Sciences, vol. 4, no. 1, pp. 39-103, 1995.

[59] A.-K. Carstensen and J. Bernhard, "Design science research - a powerful tool for improving methods in engineering education research," European Journal of Engineering Education, vol. 44, no. 1-2,pp. 85-102, 2019.

[60] A.-K. Carstensen and J. Bernhard, "Make links: Overcoming the threshold and entering the portal of understanding," in Threshold concepts in practice, R. Land, E. T. Meyer, and M. T. Flanagan, Eds. Rotterdam: Sense Publishers, 2016, pp. 209-220.

[61] A.-K. Carstensen, Connect: Modelling Learning to Facilitate Linking Models and the Real World through Lab-work in Electric Circuit Courses for Engineering Students (Doctoral dissertation). Linköping: Linköping University: Linköping Studies in Science and Technology, Dissertation No. 1529, 2013.

[62] J. Bernhard and A.-K. Carstensen, "Analysing and modelling engineering students' learning in the laboratory: a comparison of 
two methodologies," in Research in Engineering Education Symposium, Dublin, 2015.

[63] A. Tiberghien, "Labwork activity and learning physics - an approach based on modeling," in Practical work in science education, J. Leach and A. Paulsen, Eds. Fredriksberg: Roskilde University Press, 1998, pp. 176-194.

[64] E. de Graaff and A. Kolmos, "Characteristics of problem-based learning," International Journal of Engineering Education, vol. 19, no. 5, pp. 657-662, 2003.

[65] A. Kolmos and E. de Graaff, "Problem-Based and Project-Based Learning in Engineering Education: Merging Models," in Cambridge Handbook of Engineering Education Research, A. Johri and B. Olds, Eds. Cambridge: Cambridge University Press, 2014, pp. 141-160.

[66] T. Ryberg, J. Davidsen, and V. Hodgson, "Problem and project based learning in hybrid spaces: nomads and artisans," in 10th International Conference on Networked Learning, 2016, pp. 200209.

[67] C. Heath, "Embodied action: video and the analysis of social interaction," in Qualitative Research, D. Silverman, Ed. 4th ed. London: Sage, 2016, pp. 311-327.

[68] C. Goodwin, Co-operative Action. New York, NY: Cambridge University Press, 2018.

[69] P. ten Have, Doing Conversation Analysis: A Practical Guide, 2nd ed. Los Angeles: SAGE, 2007.

[70] I. Hutchby and R. Wooffitt, Conversation analysis: principles, practices and applications. Oxford: Polity, 1998.

[71] P. Linell and D. Persson Thunqvist, "Moving in and out of framings: activity contexts in talks with young unemployed people within a training project," Journal of Pragmatics, vol. 35, no. 3, pp. 409-434, 2003.

[72] C. Goodwin, "Pointing as situated practice," in Pointing: Where language, culture and cognition meet, S. Kita, Ed. Mahwah, NJ: Erlbaum, 2003,pp. 217-241.

[73] S. T. Stubbs, "Design drawing in instructional design at Brigham Young University's center for instructional design: A case study," Brigham Young University, Provo, UT, 2006.

[74] J. Bernhard, "A tool to see with or just something to manipulate? Investigating engineering students' use of oscilloscopes in the laboratory," in SEFI annual conference, Orleans, 2015.

[75] C. J. Atman, J. R. Chimka, K. M. Bursic, and H. L. Nachtmann, "A comparison of freshman and senior engineering design processes," Design Studies, vol. 20, no. 2, pp. 131-152, 1999.

[76] C. J. Atman, R. S. Adams, M. E. Cardella, J. Turns, S. Mosborg, and J. Saleem, "Engineering Design Processes: A Comparison of Students and Expert Practitioners," Journal of Engineering Education, vol. 96, no. 4, pp. 359-379, 2007.

[77] M. E. Cardella, C. J. Atman, J. Turns, and R. S. Adams, "Students with Differing Design Processes as Freshmen: Case Studies on Change," International Journal of Engineering Education, vol. 24, no. 2, pp. 246-259, 2008.

[78] N. Wolmarans, "Navigating Boundaries: Moving Between Context and Disciplinary Knowledge When Learning to Design," in Analyzing Design Review Conversations, R. Adams and J. Siddiqui, Eds. West Lafayette, IN: Purdue University Press, 2015, pp.97-114.

[79] N. Wolmarans, "Inferential reasoning in design: Relations between material product and specialised disciplinary knowledge," Design Studies, vol. 45, Part A, pp. 92-115, 2016.

[80] D. Hammer and A. Elby, "Tapping Epistemological Resources for Learning Physics," Journal of the Learning Sciences, vol. 12, no. 1, pp. 53-90, 2003.

[81] M. Welzel and W. M. Roth, "Do interviews really assess students' knowledge?," International Journal of Science Education, vol. 20, no. 1, pp. 25-44, 1998.

[82] C. Campbell, W. M. Roth, and A. Jornet, "Collaborative Design Decision-making as Social Process," European Journal of Engineering Education, 2018.

[83] A. Still and A. Costall, "Introduction: In place of cognitivism," in Cognitive psychology in question, A. Still and A. Costall, Eds. Brighton: Harvester Press, 1987, pp. 1-16.

[84] S. Lelas, "Science as technology," The British Journal for the Philosophy of Science, vol. 44, no. 3, pp. 423-442, 1993.

[85] M. Brereton, "Distributed Cognition in Engineering Design: Negotiating between Abstract and Material Representations," in
Design Representation, G. Goldschmidt and W. L. Porter, Eds. London: Springer, 2004, pp. 83-103.

[86] K. M. Murphy, "Collaborative imagining: The interactive use of gestures, talk, and graphic representation in architectural practice," in Semiotica vol. 2005, ed, 2005, pp. 113-145.

[87] K. Henderson, On Line and On Paper: Visual Representations, Visual Culture, and Computer Graphics in Design Engineering. Cambridge, MA: The MIT Press, 1999.

[88] C. Goodwin, "Seeing in Depth," Social Studies of Science, vol. 25, no. 2, pp. 237-274, 1995 .

[89] E. Hutchins, Cognition in the Wild. Cambridge, MA: The MIT Press, 1995.

[90] G. Stahl, "Theories of Cognition in Collaborative Learning," in The International Handbook of Collaborative Learning, C. E. HmeloSilver, C. A. Chinn, C. K. K. Chan, and A. M. O'Donnell, Eds. New York, NY: Routledge, 2013,pp. 74-90.

[91] G. Stahl, "The Group as Paradigmatic Unit of Analysis: The Contested Relationship of Computer-Supported Collaborative Learning to the Learning Sciences," in Reflections on the Learning Sciences, M. A. Evans, M. J. Packer, and R. K. Sawyer, Eds. New York, NY: Cambridge University Press, 2016, pp. 76-102.

[92] E. A. Kinsella and A. Pitman, "Phronesis as Professional Knowledge: Practical Wisdom in the Professions." Rotterdam: Sense, 2012.

Jonte Bernhard received a M.Sc. in engineering physics with a material science specialization in 1980 at Uppsala University, Sweden, and a Ph.D. (Engineering) in solid state physics from the same university in 1987. Since 2012 he is full professor in Engineering Education Research at Linköping University and also since 2018 Deputy Editor of European Journal of Engineering Education.

Anna-Karin Carstensen received a M.Sc. in engineering physics with a medical technology specialization in 1983 at Linköping University, Sweden, and a Ph.D. (Engineering) in engineering education research from the same university in 2013. She is a Senior Lecturer at the Department of Computer Science and Informatics at Jönköping School of Engineering.

Jacob Davidsen, received a M.A. degree in human-centered informatics in 2010 and a Ph.D. in 2014 at Aalborg University, Denmark. Since 2018 he has been an Associate Professor at the Department of Communication and Psychology, Aalborg University.

Thomas Ryberg, received a M.A. degree in 2003 and his Ph.D. in 2007 at Aalborg University, Denmark. Since 2017 he has been a Full Professor at the Department of Communication and Psychology, Aalborg University. 